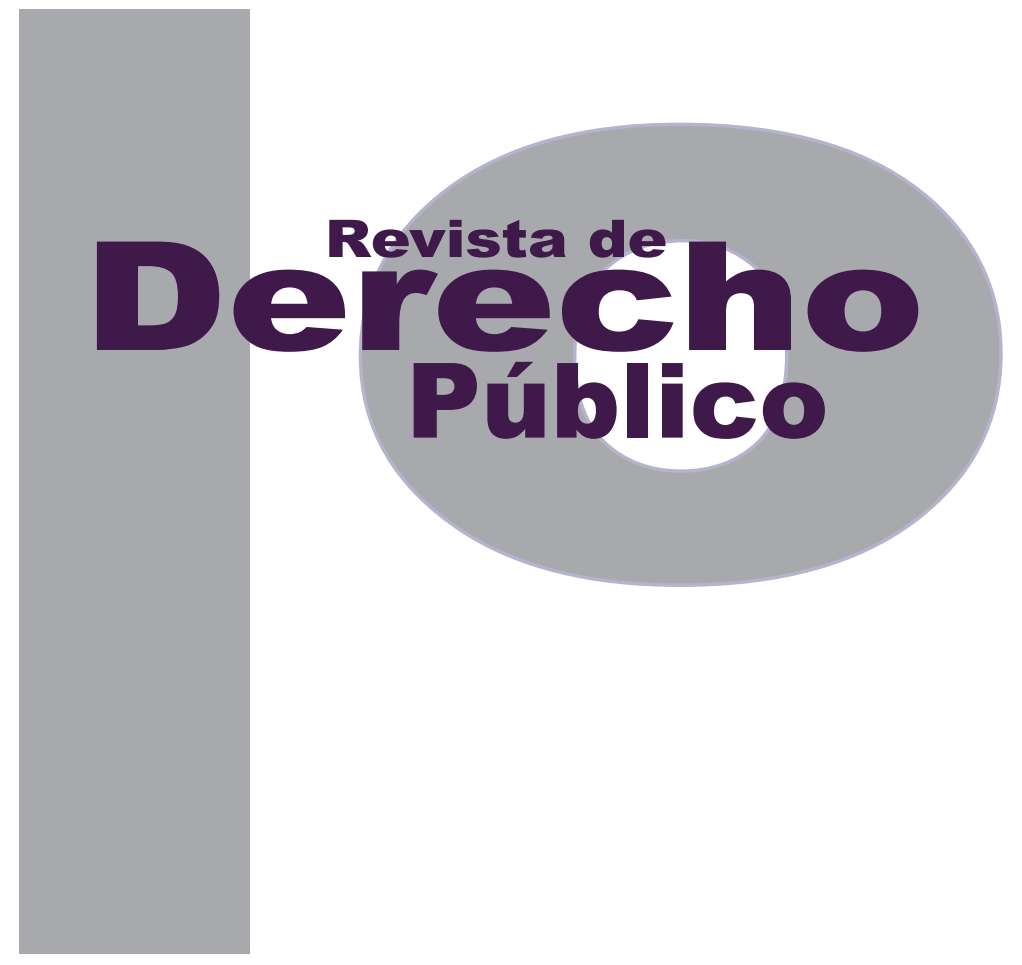

\title{
EL DERECHO A LA INFORMACIÓN PÚBLICA EN MÉXICO
}

Carlos Manuel Rosales

Universidad de los Andes

Facultad de Derecho

Revista de Derecho Público N. ${ }^{\circ} 30$

Enero - Junio de 2013. ISSN 1909-7778 


\title{
El derecho a la información pública en México
}

\author{
Carlos Manuel Rosales*
}

\section{RESUMEN}

El trabajo presenta el significado y utilidad del derecho a la información. En especial, se analiza el establecimiento y adaptación de esta prerrogativa ciudadana en el sistema positivo mexicano.

PALABRAS CLAVE: derechos fundamentales, derecho a la información, transparencia, rendición de cuentas.

\section{ABSTRACT}

This work presents the meaning and usefulness of the right to the information. Especially, it will analyze the instauration and adaption from this civil prerogative in the positive Mexican system.

KEY WORDS: Fundamental rights, right to the information, transparency, accountability. 


\section{SUMARIO}

Introducción - I. EL DERECHO A LA INFORMACIÓN - A. Concepto del derecho a la información - B. Objeto y principios del derecho a la información pública - II. EL DERECHO A LA INFORMACIÓN EN MÉXICO - A. Principios de la Ley Federal de Transparencia y acceso a la información pública gubernamental - B. Interpretación judicial del derecho a la información - III. CONCLUSIONES - Bibliografía. 


\section{Introducción}

El derecho a la información es una prerrogativa civil, que sirve para que la sociedad tenga conocimiento de la actuación del Gobierno y de las organizaciones o instituciones que administran, obtienen o reciben recursos provenientes del erario público. Asimismo, tiene como función servir de instrumento para transparentar la actuación estatal y la rendición de cuentas de los servidores públicos. ${ }^{1}$

La existencia y utilidad de este derecho depende del interés de la ciudadanía para convertir esa información en un instrumento democrático. Este trabajo intenta demostrar la importancia de este mecanismo de control de las actividades del Estado, en especial en el caso de México. ${ }^{2}$ Para comenzar, se presenta la naturaleza jurídica, acepción, objetivos y elementos del derecho a la información. Posteriormente, se expone su incorporación en el sistema positivo mexicano, para mostrar el estado legal que guarda esta garantía, y poder ofrecer un conjunto de conclusiones sobre este tema.

La finalidad es que se conozca y difunda el significado, metas y utilidad del derecho a la información pública, así como exponer cómo se encuentra legislado este derecho ciudadano en México.

1 MieRES, Luis Javier, "la regulación de los contenidos audiovisuales" en CARPIZO, Jorge y CARBonelL, Miguel (coords.), Derecho a la información y derechos humanos, Ed. UnAm, México, 2000, p. 252.

2 En el caso de México, el derecho a la información fue incorporado en 1977 como garantía constitucional. Pero hasta el año 2003 se pudo ejercer este derecho fundamental con la promulgación de la Ley Federal de Transparencia y Acceso a la Información Pública.

\section{EL DERECHO A LA INFORMACIÓN}

Los regímenes democráticos comparten varios elementos mínimos para considerar que cuentan con una auténtica democracia. Sobre este tema, Laurence Whitehead se apega al criterio de Robert Dahl, ampliado por Philippe C. Schimtter y Terry Lynn Karl. Para ellos, una de las condiciones para llamar a un régimen democrático es que "los ciudadanos tengan el derecho de buscar fuentes alternativas de información"3.

La información responde a la necesidad del ser humano de comunicarse y de querer saber lo que los demás han expresado; responde a un requerimiento que en determinado momento se vuelve un derecho fundamental, pues, como hombres de libertad, debemos tener el derecho de expresarnos, de informar y de ser informados. Tal prerrogativa natural deberá estar garantizada por el Estado y definida por la sociedad, puesto que ella es la que le asigna a esta su valor y función. ${ }^{4}$ La libertad de información ciudadana comprende:

el derecho a investigar y acceder a las fuentes de información, a transmitir la información de cualquier forma y a través de cualquier medio sin censura ni restricciones preventivas y el derecho a recibir, seleccionar y rectificar las informaciones difundidas, debiendo el Estado, sus agentes y órganos respetar tales derechos, garantizarlos, como promoverlos, contribuyen-

3 Águila, Rafael, Manual de ciencia política, Ed. Trotta, Madrid, 2000, p. 156.

4 QuezAdA, Bianca Paola, (coord.), Derecho de acceso a la información pública en los Estados Unidos, Ed. Universidad Iberoamericana, México, 2001, p. 28. 
do al desarrollo del pluralismo informativo, previniendo la existencia de censuras directas o indirectas, administrando con transparencia, racionalidad y justicia el acceso a las frecuencias radioeléctricas, impidiendo la existencia de monopolios u oligopolios respecto de los medios o insumos necesarios para producir la información escrita, por cable o de cualquier otro modo o medio, como por último, impidiendo la constitución de monopolios públicos o privados sobre todos los tipos de medios de comunicación social. ${ }^{5}$

De acuerdo a lo anterior, podemos concluir que la información libre es una de las condiciones de la sociedad en libertad y constituye un elemento de una sociedad democrática. ${ }^{6}$

Además, la información pública es un catalizador de la participación social: quien tiene más y mejor información goza de mayores posibilidades de participar e incidir en la toma de decisiones concernientes a políticas públicas, programas y proyectos, tanto públicos como privados. $^{7}$ De esta forma, el ejercicio de la libertad de comunicación de los ciudadanos se vincula con el poder, ya que para eso es el acceso a la información, para interesarnos por el quehacer gubernamental y establecer una línea de intercambio con el gobierno, al que no solo exigimos

5 NogueiRA, Humberto, "El derecho a la información en el derecho constitucional comparado en Iberoamérica y Estados Unidos", en CARPIZO, Jorge y Carbonell, Miguel, (coords.), op. cit., p. 26.

6 Melgar Adalid, Mario, El derecho a la información, [en línea], http:// www.juridicas.unam.mx/publica/librev/rev/facdermx/cont/189/dtr/dtr4. pdfp.123, [consultada el 22 de diciembre del 2012].

7 Bustillos, Isabel, "Diagnóstico del acceso a la información ambiental en México", en El derecho de acceso a la información en México: un diagnóstico de la sociedad, Ed. IFAI, México, 2004, p. 21. que dé a conocer las decisiones que toma, sino los procesos de selección que sigue ante esas decisiones. $^{8}$

Como se observa, el derecho a contar con información es fundamental para conocer la actuación de los funcionarios públicos y el destino del erario; para someter a juicio a nuestras autoridades, saber si seguimos depositando en ellas nuestra confianza y si continuáremos dejándoles nuestra representación; y, a la vez sirve, para que los funcionarios estatales puedan hacer públicas sus actividades y ejecutorias.

El acceso a la información es un derecho de enorme valor, que sin duda impulsa la construcción de sociedades más justas, equitativas y corresponsables en la gestión de los asuntos públicos, a la vez que coadyuva al fortalecimiento del patrimonio social y a la vida democrática del país. A continuación se elucida el concepto de derecho a la información.

\section{A. Concepto del derecho a la información}

La palabra información viene de la raíz in-formare (poner en forma) y es una de las nociones más importantes de las libertades individuales en un sistema democrático. En la doctrina se ha hecho una clara distinción entre el derecho de la información y el derecho a la información, por lo que se abordarán ambos conceptos, para precisar su respectivo alcance.

\footnotetext{
8 PESCHARD, Jacqueline, "La transparencia y el acceso a la información pública federal”, en Derecho a la información, Ed. Asociación Mexicana de Derecho a la Información, AC., México, 2009, pp. 118-119.
} 
El derecho de la información es "la rama del derecho público que tiene por objeto el estudio de las normas jurídicas que regulan los alcances y los límites del ejercicio de las libertades de expresión y de información a través de cualquier medio"9. Otra definición es la siguiente: "Conjunto de estudios doctrinales realizados sobre el sistema de normas jurídicas que regulan la comunicación y recepción de información de interés público dirigida a conformar la opinión pública, así como al sistema de normas constitutivas de dicho objeto de estudio" ${ }^{10}$.

Por lo que el derecho de la información se refiere al estudio y sistematización de las disposiciones jurídicas positivas en materia de información. Es decir, que incluye, pero no se agota, en el estudio de las libertades de recibir, buscar y difundir informaciones y opiniones. ${ }^{11}$

Por otro lado, el derecho a la información implica la facultad que tiene todo individuo de recibir, acceder, investigar, buscar y difundir información. Como derecho fundamental incluye las facultades de acceso a los archivos, registros y documentos públicos; la obtención de dichos documentos; la orientación sobre dónde obtener la información que solicita; así como la decisión de qué medio se solicita. ${ }^{12}$ Para Ernesto

9 ANDRADE, Julián, "El derecho a la información, los derechos humanos y el periodismo", [en línea], http://biblio.juridicas.unam.mx/libros/1/7/22. pdf.

$10 \quad$ Idem, p. 450.

11 LóPEZ, Sergio, "El derecho a la información como derecho fundamental", op. cit., p. 173.

12 Madero Estrada, José Miguel, "Contenidos del derecho fundamental a la información pública en Nayarit", en Derecho a la información: valores y perspectivas, México, Instituto de Transparencia e Información Pública del Estado de Jalisco, 2009, p. 104.
Villanueva citado por Samuel Bonilla Núñez, el derecho a la información es entendido como:

1. El derecho a atraerse información incluye las facultades de i) acceso a los archivos, registros y documentos públicos y, ii) la decisión de qué medio se lee, se escucha o se contempla.

2. El derecho a informar incluye las i) libertades de expresión y de imprenta y, ii) el de constitución de sociedades y empresas informativas.

3. El derecho a ser informado incluye las facultades de i) recibir información objetiva y oportuna, ii) la cual debe ser completa, es decir, el derecho a enterarse de todas las noticias y, iii) con carácter universal, o sea, que la información es para todas las personas sin exclusión alguna. ${ }^{13}$

Este derecho público subjetivo es de interés social e implica el ejercicio de tres facultades "distintas pero interrelacionadas a saber: recibir, investigar y difundir informaciones"14. Para ilustrar de manera más específica las diferencias entre ambos conceptos, podemos analizar la siguiente distinción que propone José Robles:

El derecho de la información es una de las disciplinas de las ciencias del derecho que regula y protege las libertades informativas. El derecho a la información es un derecho subjetivo público -es decir, puede ser ejercido o no por una persona ante el Estado-, que es campo de estudio y razón de ser del derecho de la información. A su vez, el derecho de acceso a la

13 BONILla NúÑEz, Samuel, "Derecho de acceso a la información pública. Un derecho en construcción”, en Justicia. Punto de Equilibrio, México, 2008 , p. 4

14 Melgar Adalid, Mario, El derecho a la información, op. cit. 
información pública es una de las derivaciones del derecho a la información y es la facultad que tienen las personas para acceder a la información en poder de las entidades públicas ${ }^{15}$.

De esta manera, el derecho de la información se puede definir como el conjunto de normas jurídicas que regulan y tutelan las libertades, garantías, facultades y delimitaciones que integran el derecho a la información. Este acceso a la información nos permitirá conocer qué decisiones toma el gobierno y esto es algo que se inscribe como derecho y exigencia de la sociedad, en un contexto democrático. ${ }^{16}$

La importancia de la información es innegable, pues consideraciones de carácter político, social y económico la convierten en un bien susceptible de ser apropiado, "dado su valor patrimonial inherente que radica ya no tanto en su contenido, sino en su destinación"17.

\section{B. Objeto y principios del derecho a la información pública}

La información se ha establecido como un bien público que sirve para el control de los asuntos públicos y de gobierno, debiendo el Estado y sus diversos órganos garantizar efectivamente su circulación e impedir que ella sea obstaculizada. Así, la libertad de información protege la democracia de las tentaciones autocráticas y

15 Robles Hernández, José Guadalupe, Derecho de la Información y comunicación Pública, Ed. Universidad de Occidente, México, 2004, p. 23.

16 PeschARD, Jacqueline, "La transparencia y el acceso a la información pública federal”, op. cit., p. 117.

17 Ibidem, p. 117 las acciones tendientes a evitar la opinión ciudadana, generando frenos y contrapesos frente al ejercicio del poder. ${ }^{18}$

Las características del derecho a la información son: la facultad de recibir, investigar y difundir información; la información deber ser veraz, completa, objetiva, oportuna y asequible por igual a todos; es un derecho de toda persona que incide en su perfeccionamiento, sobre todo en la esfera social y en su capacidad para tomar decisiones y participar en la construcción democrática; en el ejercicio de este derecho están involucrados el Estado, los medios de comunicación y los particulares; los entes públicos tienen el deber de facilitar el intercambio de información, así como garantizar el acceso a ella. Además, tienen la obligación de proporcionar y poner a disposición de los particulares la información pública que transparente su gestión. ${ }^{19}$

Es menester mencionar que el derecho a la información no es absoluto. Las restricciones a esta prerrogativa son: “1) la moral pública, especialmente la protección de grupos vulnerables (niños y jóvenes); 2) la seguridad nacional; 3) la defensa del Estado democrático; 4) el orden y la seguridad públicas, y 5) la salud pública. Por otro lado, las libertades contenidas en el derecho a la información pueden entrar en colisión con el derecho a la intimidad o vida privada, y el derecho al honor y la reputación"20.

18 Idem, p. 154.

19 Juncon Esteban, María Alicia, El derecho de acceso a la información: de la penumbra a la transparencia, Ed. Porrúa, México, 2003, pp. 2627.

20 LÓPEZ, Sergio, "El derecho a la información como derecho fundamental”, op. cit., pp. 170-71. 
Los principios que gobiernan el derecho a la información nos permiten establecer las reglas prácticas para su ordenación, así como orientar y facilitar su interpretación y aplicación. ${ }^{21}$ Por lo que a continuación, se exponen los principios más importantes para el profesor Daniel Soto Gama:

Principio de Transparencia, implica que toda la información o cúmulo de datos que el Estado posee, esté disponible al ciudadano sin obstáculos, libre de toda manipulación, sea completa, oportuna y entendible para todos, proporcionando así, un instrumento por medio del cual la ciudadanía pueda manifestar su preocupación e interés por los asuntos públicos que tarde o temprano tendrán consecuencias en su vida.

Principio de Publicidad, debe concebirse de dos maneras: primero, como la obligación del Estado de publicar el máximo de información posible y, segundo, como la facultad de todo individuo de publicar la información que este desee sobre los actos de gobierno, mientras esta no se encuentre comprendida dentro del ámbito de excepciones del derecho a la información.

\section{Principio de Calidad o Fidelidad de la Informa-} ción, busca prevenir que todo individuo se vea afectado en el ejercicio de su derecho fundamental a la información, por recibir información manipulada, incompleta o poco clara.

Principio de Facilidad de Acceso a la Información, debe prevenir la asistencia a personas con alguna discapacidad. ${ }^{22}$

21 Soto Gama, Daniel, Principios generales del derecho a la información, Ed. Instituto de Transparencia y Acceso a la Información Pública del Estado de México y Municipios, México, 2010, p. 170.

22 Vid, considerando tercero, sentencia del Juicio para la Protección de los Derechos Político-Electorales del Ciudadano, Exp. SUPJDC-216/2004.
En la interpretación del Principio de Ámbito

Limitado de Excepciones, debe concebirse al acceso como obligación y al límite como excepción.

Principio de Gratuidad y Mínima Formalidad, debe considerar la gratuidad en la reproducción de la información solicitada por personas con salario mínimo, que no sepan leer ni escribir, discapacitadas, invidentes, adultos mayores o indígenas. Así como, también, la eliminación de una solicitud por escrito cuando la información pueda proporcionarse el mismo día. ${ }^{23}$

Principio de Protección de Datos Personales, previene que los individuos que han proporcionado información personal al Estado, se vean afectados por su mal uso. Permite además que los ciudadanos puedan saber el uso y destino de dicha información, así como su rectificación en el caso de haber sido modificados o no estar actualizados. ${ }^{24}$.

Asimismo, el derecho a la información está condicionado por la veracidad, pues es conveniente delimitar a qué tipo de información es necesario exigirle la cualidad de ser veraz.

El requisito de veracidad exhorta a que a todo hecho noticiable se le apliquen todas las diligencias obligatorias, así como también que todos los procedimientos comprobatorios sean llevados a cabo con todo el profesionalismo

Cfr, Villanueva, Ernesto, Derecho de acceso a la información pública en México. Indicadores legales, Ed. Limac, México, 2005, p. 22.

Sото GAmA, Daniel, op. cit., pp. 171-172. Otro principio que se considera relevante es el de máxima revelación: "establece la presunción de que toda la información en poder de los órganos públicos debe ser objeto de revelación y que esta presunción puede obviarse sólo en circunstancias muy restringidas". Idem, p. 153. 
dado que solo así se puede suponer que la información difundida revista el carácter de veraz, ello representa ponderar la buena fe en la obtención de la información. ${ }^{25}$

Un elemento correlacionado con el derecho a la información es la transparencia; esta constituye un medio para un fin universal de ilimitada aplicación en la vida social e individual. Es una herramienta que acoge el máximo ideal: la consecución del bien común. ${ }^{26}$ Esto implica que toda la información o cúmulo de datos que se posee, esté disponible al ciudadano sin obstáculos, libre de toda manipulación. ${ }^{27}$

La transparencia se ha colocado en la categoría de lo políticamente correcto pero aún está lejos de alcanzar tal reconocimiento en las prácticas burocráticas cotidianas. $Y$ esto se debe, entre otras causas, a que la transformación cultural de aceptar, comprender y asimilar la transparencia como condición consubstancial del quehacer público tomará algunas generaciones. ${ }^{28}$

Por lo que la transparencia y el acceso a la información pública son los insumos básicos para que la sociedad civil tenga contacto con las políticas públicas. También, permite conocer el funcionamiento de la burocracia, evaluarla y en su caso, sancionarla. Con este acceso a la informapolíticos", en Derecho a la información: valores y perspectivas, Ed. Instituto de Transparencia e Información Pública del Estado de Jalisco, México, [en línea], http://www.itei.org.mx/v3/documentos/divulgacion/ Derecholnformacion.pdf, p. 41.

27 Sото Gama, Daniel, op. cit., p. 152.

28 Bonilla NúÑEz, Samuel, op. cit., p. 12 ción se puede crear una comunicación entre el Gobierno y la ciudadanía. ${ }^{29}$

Con lo expuesto, podemos considerar que el acceso a la información es un instrumento primordial para combatir la corrupción, hacer realidad el principio de transparencia en la gestión pública y mejorar la calidad democrática. ${ }^{30}$ Con estos instrumentos, se propone generar el control ciudadano del quehacer público, mediante la información y la publicidad, y construir con ello una cultura de rendición de cuentas.

Para concluir este apartado, deseo mencionar que para lograr sociedades más democráticas tenemos que robustecer, por un lado, los instrumentos que nos permitan el fácil y libre acceso a la información como parte de la rendición de cuentas y, por otro lado, para que el sistema democrático se consolide, necesitamos ciudadanos más participativos.

\section{EL DERECHO A LA INFORMACIÓN EN MÉXICO}

Los primeros antecedentes del derecho a la información en México están contenidos en las Constituciones de 1824, 1857 y 1917, que establecieron que los ciudadanos tenían derecho a la libre expresión y a decir lo que a cada quien le plazca y le satisfaga; excepto, cuando se ata-

29 VAllarta VÁzquez, María, "Demanda ciudadana la transparencia y rendición de cuentas", El derecho de acceso a la información pública, p. 39.

30 Relatoría especial para la libertad de expresión, Comisión Interamericana de los Derechos Humanos, Organización de los Estados Americanos, Estudio especial sobre derecho a la información, EE. UU., 2007, p. 6. 
que a la moral, los derechos de terceros o de las personas, o cuando se ataque el orden público. ${ }^{31}$ Pero no se estipuló de manera concreta el "derecho a la información".

En 1976, se consideró el derecho a la información en el Plan Básico de Gobierno (1976-1982), como una de las metas:

[...] El derecho a la información significa superar la concepción exclusivamente mercantilista de los medios de comunicación. Significa renovar la idea tradicional que entiende el derecho de información como equivalente a la libertad de expresión: es decir, libertad para el que produce y emite, pero que, se reduciría, si ignora el derecho que tienen los hombres como receptores de la información "La existencia de un verdadero derecho a la información, enriquece el conocimiento que los ciudadanos requieren para una mejor participación democrática, para un ordenamiento de la conducta individual y colectiva del país conforme a sus aspiraciones"32.

Este plan gubernamental proponía una reforma política que contenía varias medidas basadas en los principios de apertura democrática, pluralismo ideológico, fortalecimiento de la sociedad civil y reafirmación de la presencia estatal en la sociedad. ${ }^{33}$

31 Granados Chapa, Miguel Ángel, "Disposiciones reguladoras de la comunicación", en Derecho a la Información, p. 34.

32 SÉNECA (sobrenombre), Memoria de concurso para obtener el grado de licenciatura, [en línea], http://caipec.org.mx/wpcontent/ uploads/2011/03/el_derecho_de_acceso_a_la_informacion_pública_ en_mexico_y_la_reforma_al_art._60_constitucional_-mención_honorífica_seneca_colima.pdf, pp. 4-5. Consultado el 22 de diciembre del 2012.

33 Bonilla NúNÉEz, Samuel, op. cit., p. 8.
En 1977, se integró a la Constitución esta garantía individual, quedando protegido el derecho a la información. Este derecho formó parte de una reforma política que tenía como eje el acceso de los partidos políticos a los medios de comunicación, fundamentalmente, el acceso a la radio y la televisión. Sin embargo, la expresión constitucional: "El derecho a la información será garantizado por el Estado", no menciona qué es ese derecho, ni cómo (en su caso) lo garantiza el Estado.

En las siguientes décadas, el tema del derecho a la información no se atendió debidamente por la autoridad y fue poco estudiado por la academia, por lo que esta garantía individual tuvo una utilización casi nula. Posteriormente, el derecho a la información fue retomado por el grupo que consiguió la Presidencia de la República y que desalojó al partido hegemónico que llevaba setenta años anquilosado en el ejercicio del poder público (1929-2000). Con este cambio de actores políticos, nació una nueva época para el derecho a la información y la transparencia en México.

En el año 2003 se promulgó la Ley Federal de Transparencia y Acceso a la Información Pública Gubernamental (LFTAIPG); se estableció el Instituto Federal de Acceso a la Información (IFAI) y, posteriormente, en julio de 2007, se sistematizaron homogéneamente las reformas del artículo $6^{\circ}$ de la Constitución. ${ }^{34}$ Veamos el artículo sexto constitucional: cho a la información: valores y perspectivas, [en línea], http://www.itei. org.mx/v3/documentos/divulgacion/Derecholnformacion.pdf, p. 14 . 
Para el ejercicio del derecho de acceso a la información, la Federación, los Estados y el Distrito Federal, en el ámbito de sus respectivas competencias, se regirán por los siguientes principios y bases:

I. Toda la información en posesión de cualquier autoridad, entidad, órgano y organismo federal, estatal y municipal, es pública y solo podrá ser reservada temporalmente por razones de interés público en los términos que fijen las leyes. En la interpretación de este derecho deberá prevalecer el principio de máxima publicidad.

II. La información que se refiere a la vida privada y los datos personales protegida en los términos y con las excepciones que fijen las leyes.

III. Toda persona, sin necesidad de acreditar interés alguno o justificar su utilización, tendrá acceso gratuito a la información pública, a sus datos personales o a la rectificación de estos.

IV. Se establecerán mecanismos de acceso a la información y procedimientos de revisión expeditos. Estos procedimientos se sustanciarán ante órganos u organismos especializados e imparciales, y con autonomía operativa, de gestión y de decisión.

V. Los sujetos obligados deberán preservar sus documentos en archivos administrativos actualizados y publicarán a través de los medios electrónicos disponibles, la información completa y actualizada sobre sus indicadores de gestión y el ejercicio de los recursos públicos.

VI. Las leyes determinarán la manera en que los sujetos obligados deberán hacer pública la información relativa a los recursos públicos que entreguen a personas físicas o morales.
VII. La inobservancia a las disposiciones en materia de acceso a la información pública será sancionada en los términos que dispongan las leyes.

Este artículo establece las obligaciones regulares para toda autoridad pública en el país, lo que representa un paso más en la consolidación democrática del sistema político mexicano y, desde luego, detona la creación de nuevos marcos jurídicos para regular aquellos aspectos que todavía quedan en el vacío, por ejemplo: el perfeccionamiento de sistemas que garanticen la transparencia, y que al mismo tiempo propicien la rendición de cuentas y el control social por parte de la ciudadanía sobre el ejercicio del poder público; el diseño e implantación de instituciones formales que regulen la posesión y uso de la información personal en manos de las autoridades públicas y de los particulares y su debida protección; la institucionalización de prácticas organizacionales enmarcadas en el contexto de una ética de la responsabilidad en las dependencias públicas; así como la promoción de una cultura de la legalidad y de la transparencia que introduzca en el imaginario colectivo del pueblo mexicano la corresponsabilidad con el ejercicio democrático del gobierno. ${ }^{35}$

Desde la perspectiva del doctor Sergio López AyIlón, los motivos que dieron origen a esta reforma constitucional fueron:

a) [...] el cumplimiento normativo de un principio aceptado y válido [...] que, sin embargo, no

35 Ruvalcaba, Alfonso, "Presentación”, Derecho a la información: valores y perspectivas, Ed. Instituto de Transparencia e Información Pública del Estado de Jalisco, p. 7, [en línea], http://www.itei.org.mx/v3/documentos/divulgacion/Derecholnformacion.pdf 
podía verificarse por la ausencia de una norma constitucional explícita, y por las restricciones establecidas en la legislación secundaria;

b) [...] el nuevo texto constitucional fija el criterio de máxima publicidad como principio de interpretación para todas las autoridades, administrativas o jurisdiccionales y aún legislativas (artículo sexto constitucional in fine).

c) [...] los procesos decisorios y las decisiones tomadas por los entes públicos deberán quedar documentadas de manera fiel a la forma en que se realizaron y deberán ponerse a disposición del público. ${ }^{36}$

El objetivo de esta reforma fue muy específico: "acabar con la cultura del ocultamiento de la información, para dar paso a la cultura de la transparencia y acceso a la información y por supuesto rendición de cuentas, para posibilitar que la justicia, no sea una mera aspiración sino una realidad". ${ }^{37}$

En la actualidad, el entramado legal mexicano sitúa el derecho a la información como una garantía individual y como derecho humano a favor de cualquier persona que se encuentre en territorio nacional, con las características de irrenunciabilidad, supremacía, inalienabilidad e imprescriptibilidad. ${ }^{38}$ Es oportuno y debido

36 LÓPEZ, Sergio, op. cit., p. 169.

37 Seneca (sobrenombre), Memoria de concurso para obtener el grado de licenciatura, op. cit., p. 15. Vid, NamBo, Alfonso, "Reflexiones en torno a la Ley de Transparencia de Nayarit", en Derecho a la información: valores y perspectivas, [en línea], http://www.itei.org.mx/v3/documentos/divulgacion/Derecholnformacion.pdf, p. 142. MERINo, Mauricio, "En vísperas de la Revolución Informativa", en Salazar Ugarte, Pedro, (coord.), El derecho de acceso a la información en la Constitución mexicana, Ed. IFAI-UnAm, México, 2008.

38 Los derechos fundamentales son un concepto que despliega los derechos subjetivos públicos para garantizar el ámbito mínimo de liber- mencionar que los tratados internacionales en México se equiparan con la jerarquía normativa de la Constitución. En otras palabras, Ios tratados tienen rango constitucional, adquiriendo la supremacía y, en consecuencia, la rigidez propia de la Reforma constitucional $(2011)^{39,40}$.

El derecho de acceso a la información pública está comprendido en la categoría de los derechos humanos de cuarta generación, o sea, los derechos de la sociedad del conocimiento. ${ }^{41}$ Este derecho está contenido en los artículos 13.1 de la Convención Americana sobre Derechos Humanos y 19.2 del Pacto Internacional de

tades que es necesario para lograr la vigencia de la dignidad de las personas. Despliega también un conjunto de valores o fines directivos para el Estado constitucional, en tanto que, por un lado, devienen en límites efectivos al ejercicio del poder público y, por el otro, en una serie de garantías básicas que van a convertirse en acciones positivas del poder público en favor de las personas cuya plena eficacia legitima precisamente al Estado. Merece especial nombramiento la unilateralidad de este derecho, entendiendo que su observancia está a cargo del Estado, que es el sujeto pasivo, su receptor. Los particulares son los sujetos activos de las garantías, porque a ellos les corresponde hacerlas respetar cuando un acto de autoridad del Estado las vulnere. Este instrumento de acceso a la información es un derecho ciudadano, y es la condición sin la que no puede existir la democracia participativa.

39 Ayala Corao, Carlos, "La jerarquía constitucional de los tratados derivados de los derechos humanos y sus consecuencias", en Méndez, Silva Ricardo, (coord.), Derecho internacional de los derechos humanos. Memoria del VII Congreso Iberoamericano de Derecho Constitucional, Ed. unam, México, 2002, pp. 37 y 44. Los tratados relativos a los derechos humanos tienen, por su contenido, características que los diferencian del resto de los tratados tradicionales que se celebran para el beneficio mutuo de los Estados partes.

40 Idem, p. 51. Los derechos humanos son objeto de estudio, tanto por el derecho constitucional (interno) como por el derecho internacional. El tema de los derechos humanos ha adquirido una proyección tal, que su evolución ha permitido consolidar la formación de una nueva rama denominada "derecho internacional de los derechos humanos". Vid, Del Toro Huerta, Mario, "Retos de la aplicación judicial en México conforme a los tratados de derecho internacional de los Derechos Humanos", Secretaría de Relaciones Exteriores, La armonización de los Tratados Internacionales de Derechos Humanos en México, Ed. Programa de Cooperación sobre DD. HH. México-Comisión Europea, México, 2005, pp. 119-197.

NamBo, Alfonso, op. cit., p. 142. 
los Derechos Civiles y Políticos. ${ }^{42}$ Respecto del derecho a la información como derecho humano, la Comisión Nacional de Derechos Humanos ha definido sus características:

- Es un derecho "natural" por cuanto su razón de ser radica en la naturaleza sociable del hombre.

- Personal, porque incide en el perfeccionamiento de la persona, sobre todo en su esfera social.

- No es un derecho absoluto, es susceptible de limitaciones.

- Es público.

- Es un derecho político en el sentido de que es un derecho que posibilita, y a la vez se funda en, la participación política, participación en las funciones públicas, etcétera. ${ }^{43}$

El derecho fundamental a la información pública es uno de esos derechos que, con tan solo observarlos en el papel, cumplen una importante función de legitimidad y de realismo democrático.

\section{A. Principios de la Ley Federal de Transparencia y Acceso a la Información Pública Gubernamental}

La aprobación de la Ley Federal de Transparencia y Acceso a la Información Pública Guberna-

42 LÓPEZ, Sergio, op. cit., p. 162

$43 \mathrm{CNDH}$, Nuestros Derechos, [CD-ROM multimedia (versión 1.4)], elaborado por la CNDH a través de la Dirección General de Información Automatizada y la Secretaría Técnica del Consejo Consultivo en colaboración con la UnAM, por medio de la Dirección General de Servicios de Computo, México, 2004. mental representa uno de los logros más relevantes en México para avanzar hacia la democracia plena, y responde a una larga historia de acciones que las organizaciones de la sociedad civil han llevado a cabo para contribuir al cambio político actual. Dentro de los esfuerzos destacan los dedicados a la educación ciudadana y a las luchas por la transparencia de los procesos electorales. ${ }^{44}$

A partir de la entrada en vigor de esta ley (2003), más de 230 dependencias y entidades del gobierno federal tienen la obligación de atender solicitudes de información bajo la vigilancia del IFAl, organismo que tiene como objetivos:

Primero: Facilitar y garantizar el acceso de las personas a la información pública y el acceso y protección de los datos personales, así como contribuir a la organización de los archivos nacionales. Segundo: Promover la cultura de la transparencia en la gestión pública y la rendición de cuentas del gobierno a la sociedad, así como el ejercicio de los derechos de los gobernados en materia de acceso a la información y protección de datos personales. Tercero: Contribuir en los procesos de análisis, deliberación, diseño y expedición de las normas jurídicas necesarias en materia de archivos y datos personales, así como en los procedimientos legislativos dirigidos a perfeccionar y consolidar el marco normativo e institucional en materia de transparencia y acceso a la información pública. ${ }^{45}$

La Ley Federal de Transparencia y Acceso a la Información Pública Gubernamental se rige bajo

44 $45 \quad$ Idem 
los siguientes principios, que resume de manera acertada Daniel Soto:

a) Principio de máxima revelación, establece la presunción de que toda la información en poder de los órganos públicos debe ser objeto de revelación y que esta presunción puede obviarse solo en circunstancias muy restringidas; b) Principio de obligación de publicación, los órganos públicos están obligados a publicar la información que generen en el ejercicio de su mandato, en beneficio de la transparencia; c) Principio de ámbito limitado de las excepciones, las excepciones se establecen con claridad y en forma restringida; d) Principio de gratuidad y mínima formalidad, establece que el acceso a la información debe ser gratuito y solo estarán a cargo del solicitante los costos de reproducción; e) Principio de facilidad de acceso, todos los órganos públicos estarán obligados a establecer sistemas internos abiertos y accesibles para garantizar el derecho del público a recibir la información; f) Principio de procedencia de la revelación de información, el régimen de excepciones a la ley de acceso a información es de estricto derecho y no posibilita que otras leyes lo amplíen; g) Principio de protección de los ciudadanos que denuncian conductas ilícitas en la actividad pública, como forma de promover la cultura de acceso a la información, no se previene sanción legal alguna contra ciudadanos que divulguen información obtenida sobre conductas ilícitas en la función pública. ${ }^{46}$

Además, se estableció un sistema electrónico que permite solicitar información oportuna, dar seguimiento a respuestas de los sujetos obliga-

46 Sото GamA, Daniel, op. cit., pp. 84-85. Cfr. considerando tercero, sentencia del Juicio para la Protección de los Derechos Político-Electorales del Ciudadano, exp. SUP-JDC-216/2004. dos, control de los recursos de revisión por falta de respuesta o por inconformidad de los ciudadanos (este sistema de denomina INFOMEX). ${ }^{47}$

\section{B. Interpretación judicial del derecho a la información}

La atención que ha colocado la Suprema Corte de Justicia de la Nación (scsn), sobre el derecho a la información ha sido lacónica. En un principio, el máximo órgano judicial mexicano estimó que el derecho a la información constituía un complemento a la libertad de expresión, al ser necesario que las personas se encontraran bien informadas para poder expresarse y opinar correctamente. $^{48}$

Asimismo, la scjn consideró que conforme a diversas interpretaciones sobre las acepciones del concepto informar relacionadas con los antecedentes legislativos, significa "acción y efecto de informar e informarse", es decir, ser enterado de cualquier cosa. De esta forma, el derecho a la información se compone de una facultad doble: el derecho a dar información y el derecho a recibir información. ${ }^{49}$ La Suprema Corte al interpretar y definir el concepto de información pública deliberó lo siguiente:

comprende todos los datos que se encuentren en posesión de cualquier autoridad, entidad, órgano y organismo federal, estatal y munici-

47 GutiéRREZ, Jorge, "Website y transparencia en gobiernos municipales de Jalisco", en Derecho a la información: valores y perspectivas, p. 74, [en línea], http://www.itei.org.mx/v3/documentos/divulgacion/DerechoInformacion.pdf

CorRal JuRAdo, Javier, op. cit., p. 25.

49 Idem, p. 28 
pal, por lo cual dicha información es susceptible, en principio, de divulgarse a terceros en los términos previstos por el legislador en dicho ordenamiento legal. Sin embargo, la Corte consideró que, para que sea posible catalogar como información pública al conjunto de datos provenientes de particulares, no basta que aquélla se encuentre en posesión de los poderes públicos sino que es necesario que tal información de particulares haya sido recabada por las autoridades del Estado en ejercicio de funciones de derecho público. ${ }^{50}$

La evolución jurisprudencial del derecho a la información ha sido en tres fases. En el primer antecedente indicaron la acepción de este derecho:

La libertad de expresión y el derecho a la información son derechos funcionalmente centrales en un estado constitucional y tienen una doble faceta: por un lado, aseguran a las personas espacios esenciales para el despliegue de su autonomía y, por otro, gozan de una vertiente pública, colectiva o institucional que los convierte en piezas básicas para el adecuado funcionamiento de la democracia representativa. ${ }^{51}$

Posteriormente, la Suprema Corte estableció que el derecho a la información compele al Estado "no solamente a informar sino a asegurar que todo individuo sea enterado de algún suceso de carácter público y de interés general, por lo que ese derecho fundamental se traduce en una obligación que corre a cargo de las perso-

50 Silva Garcia, Fernando, "El derecho a la información pública en la jurisprudencia constitucional: ¿un derecho fundamental incómodo?", Cuestiones Constitucionales, $\mathrm{n}^{\circ} .24,2011$, p. 291.

51 Libertad de expresión y derecho a la información. Su importancia en una democracia constitucional. nas físicas y morales, sean estas últimas privadas, oficiales o de cualquier otra índole" 52 .

En otra oportunidad, el máximo órgano judicial volvió a interpretar este derecho considerando la calidad de la información otorgada. En este sentido, señaló que la información debía ser veraz, completa y que las autoridades debían asumir las consecuencias, por violar derechos fundamentales, al no entregarla, ${ }^{53}$

El ministro Juan Díaz Romero consideró que entre las varias interpretaciones del artículo $6^{\circ}$ constitucional, se encuentra la que contiene la obligación del Estado de informar al pueblo en general:

"sobre la verdad de lo que acontece; no paliar esas verdades y no llegar al engaño. Este caso es una hipótesis en que se concreta la garantía del derecho a la información, en donde tenemos dos sujetos: Uno, el Estado que está obligado a proporcionar la información y, el segundo, el pueblo en general que tiene derecho a recibir una determinada información apegada a la verdad" 54 .

Así, el derecho a la información es el derecho a ser informado con veracidad, objetividad y oportunidad, así como el lograr el acceso a esta. ${ }^{55}$

52 Bonilla NúÑEz; Samuel, op. cit., p. 14.

53 Derecho a la información. La Suprema Corte interpretó originalmente el artículo $6^{\circ}$ como garantía de partidos políticos, ampliando posteriormente ese concepto a garantía individual y a obligación del Estado a informar verazmente.

54 Díaz Romero, Juan, El derecho a la información, Ed. scun, México, 2000, p. 24.

55 Melgar Adalid, Mario, "El derecho a la información", [en línea], http:// www.juridicas.unam.mx/publica/librev/rev/facdermx/cont/189/dtr/dtr4. pdfp.1234. Consultada el 22 de diciembre del 2012. 
Para concluir este acápite debemos conocer cómo es considerado actualmente el derecho a la información por la scun:

1. La información constituye un factor de control del ejercicio del poder público, dado que los diversos entes estatales se encuentran obligados a dar a conocer cada uno de sus actos públicos, que sean de interés general, para transparentar el debido cumplimiento de las funciones que tengan encomendadas, salvo los datos que sean catalogados como confidenciales.

2. El desarrollo del derecho de acceso a la información se ha enfrentado a diversas problemáticas, resistencias y deformaciones, principalmente por la heterogeneidad con la que se legisló sobre el particular en las distintas entidades federativas de la República, provocando una diversidad perjudicial para su consolidación, ante la falta de una "guía constitucional".

3. Se facultó a los Estados y al Distrito Federal para que en el ámbito de sus respectivas competencias, regulen el ejercicio del derecho de acceso a la información, al tenor de los principios mínimos y bases especificados en el citado numeral. Los antecedentes constitucionales legislativos descritos son reveladores de que el Poder Constituyente dejó al arbitrio de las legislaturas de las entidades federativas elegir la forma en que deben constituir mecanismos de acceso a la información y procedimientos de revisión, con la única condición de que deben caracterizarse por su prontitud, así como sustanciarse ante órganos $\mathrm{u}$ organismos especializados e imparciales, y con autonomía operativa, de gestión y decisión, comúnmente conocidos como órganos constitucionales autónomos. ${ }^{56}$

56

Derecho a la información pública. Evolución constitucional de la regulación de esa prerrogativa.
En lo anteriormente expuesto se ha presentado y demostrado la importancia del derecho a la información; pero no basta con gozar de esta prerrogativa ciudadana, sino que debe ser bien utilizada, difundida y discutida la información obtenida. Esto involucrará a la población en los asuntos públicos, enriqueciendo, nutriendo y revitalizando el sistema democrático.

\section{CONCLUSIONES}

1. La información y la posibilidad de intercambiarla es un derecho fundamental en las democracias modernas: "El derecho a la información contribuye notoriamente a la construcción de la realidad social o, más específicamente hablando, a esa forma de realidad social que es la sociedad democrática" ${ }^{57}$. Esta prerrogativa nos permite exponer nuestros puntos de vista y conocer el de los demás. Sin embargo, este derecho a la información no es un derecho absoluto, sino que tiene algunas limitaciones como el derecho a la vida privada, la moral pública, etc. ${ }^{58}$

2. El derecho a la información es un mecanismo ciudadano que sirve para conocer y controlar la actuación del gobierno y, secundariamente, calificar su desempeño y valorar su continuidad o no en el poder. ${ }^{59}$

3. El derecho a la información es un paso más hacia la consolidación del sistema democrático

57 Vid, Morales Campos, Estela, Derecho a la información, bien público y bien privado: acceso comunitario y acceso individual, Ed. Universidad Nacional Autónoma de México, México, 2011.

Peschard, Jacqueline, op. cit., p. 129.

59 Fuentes, Luis, op. cit., p. 33. 
nacional. Empero, este derecho es desconocido socialmente y, por tanto, muy poco utilizado por la ciudadanía. Por lo que hace falta una mayor expansión social de este derecho. ${ }^{60}$

4. La transparencia nos permite apreciar con claridad lo que realiza el Estado. La transparencia constituye un esquema ideal de convivencia política, que se erige como un cuadro de control del poder, que supone frenos y contrapesos, que comprende la voluntad de aquellos que detentan la fuerza del Estado, su obligación de informar y justificar sus acciones con la posibilidad de ser castigados por sus excesos y con la garantía de los gobernados a exigir cuentas, ya sea en el marco administrativo gubernamental, vigilantes político-sociales o bien, para satisfacer intereses propios o individuales. ${ }^{61}$

5. En sentido jurídico, la transparencia es el derecho de los ciudadanos a conocer y analizar las actividades del Estado. Así, esta garantía de control sobre las acciones del Estado nos acerca más a la justicia y al desarrollo social y, por tanto, al fortalecimiento del Estado. ${ }^{62}$ Por lo que la transparencia en una sociedad abierta avala el acceso a la información, favoreciendo de ese modo la transparencia del uso del poder. ${ }^{63}$

6. El cumplimiento con las obligaciones en materia de transparencia a través del suministro de información por parte del Estado es otro de los

60 Bustillos, Isabel, op. cit., p. 35.

$61 \quad$ Idem, p. 31.

62 Villanueva, Ernesto, op. cit., pp. 25-40.

63 Idem, pp. 40-42. factores que inciden en el proceso de culturización en materia de transparencia.

7. A pesar del avance en el tema de la transparencia, la mayoría de los ciudadanos carecen de un conocimiento claro y de incidencia a este respecto. ${ }^{64}$ En ello radica la importancia de difundir este tema a través de todos los medios disponibles, de buscar espacios que reditúen en conocimiento para la sociedad. Esto significa transitar de la mera cultura del informe anual hacia la cultura del otorgamiento a la ciudadanía de la información gubernamental, como un gesto básico de responsabilidad con la gente.

8. La cultura de la transparencia debe ser un quehacer cotidiano, no una nueva carga burocrática. Es necesario sensibilizar a los servidores públicos sobre la importancia del buen manejo de documentos, ya que cuidar un documento es deber de todos los que formamos parte de un sujeto obligado, y desde nuestro trabajo cotidiano debemos tener el compromiso de salvaguardar el derecho de las personas a conocer la información pública. ${ }^{65}$

9. Instituir la transparencia como cultura es uno de los retos que representa mayor complejidad para los órganos encargados de garantizar el derecho de acceso a la información; cualquier esfuerzo que con esa finalidad se realice, precisa desarrollar estrategias que garanticen que

64 VALADÉs, Diego et al., Cultura de la Constitución en México, Ed. unAm, México, 2008, pp. 57-64 y 69-72.

65 MuÑOz, Guillermo, "Transparencia, derecho a la información y protección de datos personales", Derecho a la información: valores y perspectivas, [en línea], http://www.itei.org.mx/v3/documentos/divulgacion/ Derecholnformacion.pdf 
el mensaje trascienda en los individuos y se implante como un saber. La educación es un factor determinante en esa tarea y la responsabilidad es compartida entre el Estado y la sociedad. ${ }^{66}$

10. La rendición de cuentas se erige como un medio de control del poder, con miras a limitar y prevenir los abusos en su ejercicio, que busca equilibrar su permanencia, vigencia e inclusive alternancia como resultado de los incesantes, vibrantes, quizá heroicos y tan sangrientos excesos que engrosan el mar histórico que le comprende. Monitorea, además, a las autoridades en el cumplimiento de la ley, acción que abarca en una forma amplia tres grandes puntos: la información (derecho a la información), la justificación y, en su caso, las sanciones o castigos.

11. En México, con la reforma constitucional del 2011, los derechos fundamentales fueron elevados a la categoría de derechos humanos. Esto implica que su sistema de protección estará amparado no solo por el orden nacional, sino por los tratados internacionales reconocidos. ${ }^{67}$

12. El respeto de los derechos humanos ahora es un papel primordial de todas las instituciones del Estado mexicano, pero especialmente del Poder Judicial, siendo más garantista en la protección de los derechos humanos. Lo que si bien podría ayudar a proteger a todos de mejor manera, también traerá aparejada la necesaria intervención de esta institución en todos los

66 Delgado, Alfredo, op. cit., p. 12.

67 ORTIZ AHLF, Loretta, "Integración de las normas internacionales en los ordenamientos estatales en los países de Iberoamérica", Derecho Internacional de los Derechos Humanos, [en línea], http://biblio.juridicas. unam.mx/libros/1/342/21.pdf asuntos controvertibles, retardando o distrayendo la acción de los demás integrantes de la maquinaria estatal. ${ }^{68}$

13. Por lo que respecta al papel realizado por los tres órdenes de la Federación en México, es el municipal el que necesita de mayores reformas en materia de acceso a la información; esto porque es el primer punto de contacto de la ciudadanía con sus autoridades, y a través de ella se podría dar a conocer temas como los salarios de los servidores locales, el ejercicio del presupuesto, la determinación de las prioridades del desarrollo edilicio, entre otras.

14. A diez años de la promulgación de la Ley de Transparencia en México, siguen existiendo varias lagunas legales o normas ad hoc, que la autoridad aprovecha para reservar información sensible o para clasificar algunos documentos como secretos, quedando esta facultad a su arbitrio y discrecionalidad. Empero, hay un importante movimiento para que ya no continúe esta opacidad gubernamental y sea cada vez más transparente la actuación estatal; esta debe ser una lucha permanente de ciudadanos, académicos y onG.

\section{Bibliografía}

ÁGUILA, Rafael, Manual de ciencia política, Trotta, Madrid, 2000.

Atienza, Manuel, Las razones del derecho, unam, México, 2005.

68 Idem, p. 81 
Bonilla NúÑEz, Samuel, "Derecho de acceso a la información pública. Un derecho en construcción, revista Justicia. Punto de Equilibrio, México, 2008.

Bravo García, Ramiro, “Las innovaciones al sistema de lo contencioso electoral", Revista Teoría y praxis administrativa, vol. 1, nº. 4, México, 1987.

Carpizo, Jorge y Carbonell, Miguel, (coords.), Derecho a la información y derechos humanos, unam, México, 2000.

CNDH, Nuestros derechos, [CD-ROM multimedia versión 1.4], elaborado por la CNDH a través de la Dirección General de Información Automatizada y la Secretaría Técnica del Consejo Consultivo en colaboración de la UnAm por medio de la Dirección General de Servicios de Cómputo, México, 2004.

Díaz Romero, Juan, El derecho a la información, scjn, México, 2000.

Dworkin, Ronald, Los derechos en serio, Ariel, Barcelona, 1995.

Ferrer Mac-Gregor, Eduardo, “Interpretación conforme y control difuso de convencionalidad. El nuevo paradigma para el juez mexicano", Estudios Constitucionales, año 9, nº. 2, Chile, 2011.

Hernández Valle, Rubén, Los principios constitucionales, Escuela Judicial, Costa Rica, 1992.
Ifal, El derecho de acceso a la información en México: un diagnóstico de la sociedad, IFAI, México, 2004.

Juncon Esteban, María Alicia, El derecho de acceso a la información: de la penumbra a la transparencia, Porrúa, México, 2003,

MÉndez Silva, Ricardo, (coord.), Derecho internacional de los derechos humanos. Memoria del VII Congreso Iberoamericano de Derecho Constitucional, unam, México, 2002.

Morales Campos, Estela, Derecho a la información, bien público y bien privado: acceso comunitario y acceso individual, unAm, México, 2011.

NiETo, Santiago, Interpretación y argumentación jurídica, unam, México, 2003.

QuezadA, Bianca Paola, (coord.), Derecho de acceso a la información pública en los Estados, Universidad Iberoamericana, México, 2001.

Relatoría espeCial PARA la libertad de EXPREsión, Comisión Interamericana de los Derechos Humanos, Organización de los Estados Americanos, Estudio especial sobre el derecho a la información, EE. UU., 2007.

Robles Hernández, José Guadalupe, Derecho de la información y comunicación pública, Universidad de Occidente, México, 2004.

Salazar Ugarte, Pedro, (coord.), El Derecho de acceso a la información en la Constitución mexicana, IFAl-UnAm, México, 2008. 
scjn, El derecho a la información, scjn, México, 2000.

Secretaría de Relaciones Exteriores, La armonización de los tratados internacionales de derechos humanos en México, Ed. Programa de Cooperación sobre DD. HH. México-Comisión Europea, México, 2005.

Silva García, Fernando, "El derecho a la información pública en la jurisprudencia constitucional: ¿un derecho fundamental incómodo?", Cuestiones Constitucionales, $\mathrm{n}^{\circ}$. 24, UnAm, México, 2011.

Sото Gama, Daniel, Principios generales del derecho a la información, Ed. Instituto de Transparencia y Acceso a la Información Pública del Estado de México y Municipios, México, 2010.

ValadÉs, Diego et al., Cultura de la Constitución en México, unam, México, 2008.

Vázquez, Rodolfo, Corte, jueces y política, Fontamara, México, 2007.

Villanueva, Ernesto, Derecho de acceso a la información pública estatal: una aproximación al estado de la cuestión en México, unam-IIJ, México, 2002.

Villanueva, Ernesto, Derecho de acceso a la información pública en México. Indicadores legales, Limac, México, 2005.

V. AA., Derecho a la información, bien público y bien privado: acceso comunitario y acceso individual, unam, México, 2011.
Vv. AA., Derecho a la información. Fundamentos jurídicos de la comunicación en México, Asociación Mexicana de Derecho a la Información, A. C., México, 2009.

VV. AA., Derecho a la información: valores y perspectivas, Instituto de Transparencia e Información Pública del Estado de Jalisco, México, 2009.

Vv. AA., Dinero y contienda político-electoral, FCE, México, 2003.

\section{Legislación:}

Constitución política de los Estados Unidos mexicanos.

Ley Federal de Transparencia y Acceso a la Información Gubernamental.

\section{Jurisprudencia:}

Sentencia del Juicio para la Protección de los Derechos Político-Electorales del Ciudadano, expediente SUP-JDC-216/2004.

Libertad de expresión y derecho a la información. Su importancia en una democracia constitucional.

Derecho a la información.

Derecho a la información pública. Evolución constitucional de la regulación de esa prerrogativa. 
Documentos electrónicos:

LóPEz Ayltón, Sergio, La constitucionalización del derecho a la información, [en línea], http:// biblio.juridicas.unam.mx/libros/5/2251/13. pdf

Melgar Adalid, Mario, El derecho a la información, [en línea], http://www.juridicas.unam. mx/publica/librev/rev/facdermx/cont/189/ $\mathrm{dtr} / \mathrm{dtr} 4 . \mathrm{pdf}$

http://caipec.org.mx/wpcontent/uploads/2011/03/ el_derecho_de_acceso_a_la_informacion_pública_en_mexico_y_la_reforma_al_art._6 ${ }^{\circ}$ constitucional_-mencion_honorifica_seneca_ colima.pdf 